\title{
Epidemic to Pandemic: Just a Matter of Time
}

${ }^{1}$ Ayesha Humayun, ${ }^{2}$ Muhammad Imran Anwar, ${ }^{3}$ Saadia Shahzad Alam, ${ }^{4}$ Usman Iqbal

${ }^{1}$ Department of Public Health \& Community Medicine, Shaikh Zayed Medical Complex,Lahore

${ }^{2}$ Department of Surgery, Shaikh Zayed Medical Complex, Lahore

${ }^{3}$ Department of Pharmacology \& Therapeutics, Shaikh Zayed Medical Complex, Lahore

${ }^{4}$ Global Health \& Development, College of Public Health, Taipei Medical University, Taiwan

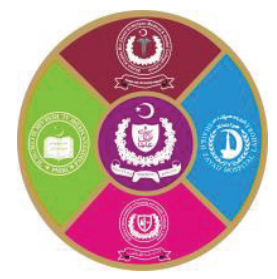

$\mathrm{E}_{\mathrm{p}}$ pidemic and pandemic potential of all respiratory diseases of zoonotic origin is well known. In recent history global public health threat was inflicted by zoonotic origin infectious diseases with pandemic potential including, Ebola and Marburg haemorrhagic fevers, severe acute respiratory syndrome (SARS), influenza A (H5N1), Middle East respiratory syndrome corona virus (MERS$\mathrm{CoV}),{ }^{1}$ and the recently discovered COVID$19 .{ }^{2}$ Change of epidemic to a pandemic is just a matter of time. A novel Corona virus 2019 (COVID-19) is appearing to be one of the rapidly transmitting diseases because of the social and economic linkages worldwide. Emerging infectious diseases (EIDs) are not new but their incidence or geographical involvement is rapidly increasing. ${ }^{3}$ Global temporal and spatial patterns of these emerging infections are studied well in literature concluding significant correlation of EIDs with socio-economic, environmental and ecological factors. It helps to identify regions as 'hotspots' for EIDs with a substantial risk of vector-borne and wildlife zoonotic emerging diseases. ${ }^{4}$

Epidemic is "the occurrence in a community or region of cases of an illness . . clearly in excess of normal expectancy". Pandemic is "an epidemic occurring over a very wide area, crossing international boundaries, and usually affecting a large number of people". ${ }^{5}$ The decision of pandemic alert is influenced by the evidence evolving from virological, epidemiological, and clinical data. ${ }^{6}$ The phases of global pandemics are divided into four i.e, inter-pandemic, alert, pandemic, and transition. ${ }^{7}$ Furthermore, the pandemic levels are classified into six phases where in phase 1 no virus circulation among animals is reported. In phase 2, a potential pandemic threat is there when domestic or wild animal circulation of virus found. Phase 3 means human sporadic cases but usually no or limited manto-man transmission. In phase 4, also called risk of pandemic, when human-to-human transmission is verified. The phase 5 depicts that there is a global pandemic underway, if human-to-human transmission found in at least 2 countries of the same region classified by World Health Organization (WHO). Phase 6 known as the pandemic phase, it keeps phase 5 criteria followed by post peak and post pandemic periods. From these phases, we can see that the last 3 phases show an actual threat and alert that concern stakeholders within countries and are required to take action with strong commitment by following instructions and warnings issued by WHO time to time accordingly with global situation. ${ }^{8}$

The pandemic risk level varies at different times among countries therefore, WHO advised to conduct their own national level risk assessments and plan management in coordination with its support. ${ }^{9}$ The International Health Regulations (2005) provide a global legal framework for public health potential threats to prevent, control, or respond to them to avoid emerging as public health emergencies of international concern (PHEICs). The risk assessment includes "preparedness," "response," and "recovery", during pandemic. ${ }^{10}$ Many developed countries took stringent initiatives during last decade to prepare for such a pandemic. Despite the fact that these countries developed and tested pandemic preparedness plans after SARS pandemic but it is unfortunate that COVID pandemic has not been tackled well. ${ }^{11}$

Recent COVID-19 outbreak is a unique kind of respiratory infection as compared to SARS (20022003) and MERS (2012-ongoing). Early in the outbreak of COVID-19 in China, genetic analysis revealed similarity and difference from SARS-CoV and the corona virus isolated from bats found to be genetically similar. ${ }^{12}$ Corona virus spread rapidly from Wuhan, Hubei, (end December 2019) only in a month within the Mainland China. In Wuhan city, travel ban was delayed which influenced epidemic progression by only 3 to 5 days in China but internationally $80 \%$ importations were not reduced until mid-February $2020 .{ }^{13}$ Disease spread was rapid in COVID-19 as compared to SARS and MERS, partly due to few factors triggering massive spread; epidemic focus in a metropolitan, Wuhan, a very 
economically active hub, well connected globally and within China; rapid connection through flights and massive rail transit; and Chinese (Lunar) New Year celebration time. This rapid spread within China and globally showed pandemic illpreparedness of economic giant countries as well as the apathetic, cold and delayed response globally in European as well as other Asian countries. Inadequate risk assessment along with limited reporting within China contributed to the rapid spread of virus throughout China and other countries. ${ }^{14}$

This COVID19 pandemic is creating a deleterious impact on human health and economics globally and dragging back countries' economies to decades. Preparedness plays a crucial role in protection of health and safety of employees and customers, limiting impact on businesses, community, economy and health system. A study of seven scenario's of COVID-19 epidemic shows that the impact on the global economy, even a contained outbreak could be significant in the short period. ${ }^{15}$ World should be learning lessons from countries that mitigated previous pandemics well such as Taiwan, it has experienced SARS in 2002. ${ }^{16}$ Public health response mechanisms were well placed by Taiwan (ROC) after 2002, which enabled them to timely recognize this new COVID-19 crisis and manage it through activated emergency management structures and processes. Taiwanese government and society responded timely and quickly by taking basic measures such as wearing face masks, social distancing and quarantine along with other necessary measures. ${ }^{17}$

This editorial highlights the importance and need of identifying the global preemptive measures to thwart current and looming pandemics. In COVID, pandemic alert phase should have been responded well to by the countries. There is a need for an extensive research on these novel emerging diseases especially corona viruses, focusing elucidation of route of transmission and pathogenesis along with development of drug and vaccines for effective prevention and control. Moreover, we should emphasize on the technology utilization to get quality, reliable data from surveillance using advanced tools, epidemiologic field investigations, case series, cohort studies to identify burden of disease and attack rates in household and in special groups. ${ }^{18}$ Vaccines and antiviral drugs are under trial but not clinically approved yet for public use. Extensive research is needed to study natural history, appraise prevention strategies, develop therapies, draw conclusions and develop and evaluate impact of targeted public health interventions. ${ }^{19}$ Developing and under-developed countries have enormous constraints, financial and social being the top most in the list. Hence, a quick contextual needs assessment and SMART objectives need to be devised to conceive and implement effective regional strategies. Based on current scenario, previous knowledge and future predictions, we can try to find answers to these questions; did we learn from two prior epidemics of corona virus? Were we well-prepared to deal with such highly contagious challenge? Did we respond timely to COVID?

Learning from previous experiences, timely and rapid information dissemination, prompt pandemic alerts and effective global collaborations can help us devise a way forward for public health threats.

\section{REFERENCES}

1. Reusken CB, Haagmans BL, Müller MA, Gutierrez C, Godeke G-J, Meyer B, et al. Middle East respiratory syndrome corona virus neutralising serum antibodies in dromedary camels: a comparative serological study. The Lancet infectious diseases. 2013;13(10):859-66.

2. Wu Z, McGoogan JM. Characteristics of and important lessons from the corona virus disease 2019 (COVID-19) outbreak in China: summary of a report of 72314 cases from the Chinese Center for Disease Control and Prevention. Jama. 2020 Apr 7; 323(13):1239-1242.

3. Morse SS. Factors in the emergence of infectious diseases. Plagues and politics: Springer; 2001. p. 8-26.

4. Jones KE, Patel NG, Levy MA, Storeygard A, Balk D, Gittleman JL, et al. Global trends in emerging infectious diseases. Nature. 2008; 451(7181):990-3.

5. Porta M. A dictionary of epidemiology: Oxford university press; 2014.

6. Doshi P. The elusive definition of pandemic influenza. Bulletin of the World Health Organization. 2011; 89:532-8.

7. World Health Organization. Pandemic influenza risk management: WHO interim guidance. World Health Organization, 2013: 6-7.

8. World Health Organization. Pandemic influenza preparedness and response. A WHO guidance document - 2009. Available from URL: https://apps.who.int/iris/bitstream/handle/10665/ 44123/9789241547680_eng.pdf;jsessionid=1F8 2125A878C00D08B9AC204EB320742?sequen ce $=1$. 
9. McCloskey B, Dar O, Zumla A, Heymann DL. Emerging infectious diseases and pandemic potential: status quo and reducing risk of global spread. The Lancet infectious diseases. 2014; 14(10):1001-10.

10. Katz R. Use of revised International Health Regulations during influenza A (H1N1) epidemic, 2009. Emerging infectious diseases. 2009; 15(8):1165.

11. Holmberg M, Lundgren B. Framing postpandemic preparedness: comparing eight European plans. Global public health. 2018; 13(1):99-114.

12. Paraskevis D, Kostaki EG, Magiorkinis G, Panayiotakopoulos G, Sourvinos G, Tsiodras S. Full-genome evolutionary analysis of the novel corona virus (2019-nCoV) rejects the hypothesis of emergence as a result of a recent recombination event. Infection, Genetics and Evolution. 2020; 79:104212.

13. Chinazzi M, Davis JT, Ajelli M, Gioannini C, Litvinova M, Merler S, et al. The effect of travel restrictions on the spread of the 2019 novel coronavirus (COVID-19) outbreak. Science. 2020; 368(6489):395-400.

14. Peeri NC, Shrestha N, Rahman MS, Zaki R, Tan Z, Bibi S, et al. The SARS, MERS and novel coronavirus (COVID-19) epidemics, the newest and biggest global health threats: what lessons have we learned? Int J Epidemiol. 2020; 49(3):717-26.

15. McKibbin WJ, Fernando R. The global macroeconomic impacts of COVID-19: Seven scenarios. 2020.

16. Yen MY, Chiu AW, Schwartz J, King CC, Lin YE, Chang SC, et al. From SARS in 2003 to H1N1 in 2009: lessons learned from Taiwan in preparation for the next pandemic. J Hosp Infect. 2014; 87(4):185-93.

17. Wang CJ, Ng CY, Brook RH. Response to COVID-19 in Taiwan: big data analytics, new technology, and proactive testing. JAMA. 2020; 323(14):1341-2.

18. Cowling BJ, Leung GM. Epidemiological research priorities for public health control of the ongoing global novel corona virus (2019nCoV) outbreak. Euro surveillance. 2020; 25(6).

19. Li JY, You Z, Wang Q, Zhou ZJ, Qiu Y, Luo R, et al. The epidemic of 2019-novel-corona virus (2019-nCoV) pneumonia and insights for emerging infectious diseases in the future. Microbes Infect. 2020; 22(2):80-5.

\section{The Authors: \\ Proceedings Editorial Team}

Prof. Ayesha Humayun (Associate Editor)

Dept. of Public Health \& Community Medicine, Shaikh Zayed Medical Complex, Lahore.

Prof. Muhammad Imran Anwar (Associate Editor) Dept of Surgery,

Shaikh Zayed Medical Complex, Lahore.

Prof. Dr. Saadia Shahzad Alam (Chief Editor)

Dept of Pharmacology\& Therapeutics,

Shaikh Zayed Medical Complex (SZMC), Lahore.

Dr. Usman Iqbal (External Associate Editor)

Global Health and Development,

College of Public Health,

Taipei Medical University, Taiwan. 